\title{
Goodman’s New Riddle of Induction
}

\author{
Dean Lubin \\ Leyton Sixth Form College, London, UK \\ Email: dean.lubin@leyton.ac.uk \\ Received September 29 $9^{\text {th }}$,2011; revised December 18 $8^{\text {th }}$, 2011; accepted December $25^{\text {th }}, 2011$
}

\begin{abstract}
In this paper, I consider Goodman's new riddle of induction and how we should best respond to it. Noticing that all the emeralds so far observed are green, we infer (project) that all emeralds are green. However, all emeralds so far observed are also grue, so we could also infer that they are grue. Only one of these inductive inferences or projections could, however, be valid. For the hypothesis that all emeralds are green predicts that the next observed emerald will be green; whereas the hypothesis that they are grue predicts that it will blue. Goodman's new riddle is the problem of saying why the inductive inference involving "green" is the valid one. Goodman's own solution appeals to the idea of entrenchment. His idea is that "green" is a more entrenched predicate than "grue" in the sense that it has figured many more times in our past projections than has "grue". In his view, this explains why "green" is projectible (can be used in valid inductive inferences) whereas "grue” isn't. I argue that this response doesn't go far enough and that we additionally need an explanation of why "green" is more entrenched than "grue"- that we are otherwise left with the unsatisfactory view that its superior entrenchment is a mere linguistic accident. I try to supplement Goodman's solution with an explanation of this kind. I argue that "grue" is not entrenched because past successful inductions involving "green" show that past projections that could have been made using what I call "grue-like" predicates_-predicates which are like "grue" except that the times featuring in their definitions are past-would have been unsuccessful.
\end{abstract}

Keywords: Induction; Grue; Entrenchment

\section{Introduction}

In Fact, Fiction and Forecast, Nelson Goodman famously poses a problem for induction-which he calls the "new riddle of induction”. In this paper, I want to consider Goodman's new riddle and how we should best respond to it.

To illustrate his new riddle, Goodman introduces the predicate "grue" (Goodman, 1983: p. 74) defined as follows:

An object is "grue" if it is first examined before $t$ (some future time) and is green; or is not first examined before $t$ and is blue.

Consider all the emeralds we have so far observed. Say there are $\mathrm{N}$ of them. These emeralds have all been observed to be green. But they are also grue (because they have been examined before $t$ and have been observed to be green). Since the $\mathrm{N}$ observed emeralds are both green and grue, there are two different inductive inferences that can be made on the basis of the observations made:

1) Premise: $N$ emeralds are green.

Conclusion: All emeralds are green.

2) Premise: $N$ emeralds are grue.

Conclusion: All emeralds are grue.

The problem is that 1) and 2) can't both be acceptable (i.e. valid or justified) inductive inferences, for 1) predicts that an emerald examined after $\mathrm{t}$ will be green; whereas 2) predicts that it will be blue.

Of course, we intuitively think that 1 ) is the valid inference. Goodman's new riddle of induction is the problem of how to distinguish valid from invalid inductive inferences - it is the problem of saying why 1) is valid whereas 2) is not. He calls this the problem of projection: when, he asks, can we project from the observed to the unobserved?

In responding to the new riddle, we clearly need a way of distinguishing projectible predicates like "green” from nonprojectible predicates like "grue". But can this be done?

\section{“Green” Is Simple, “Grue” Isn’t}

In order to make this distinction, some philosophers have tried to appeal to the idea of simplicity (As Goodman notes on p. 78, this is the kind of approach adopted by Rudolf Carnap).

On this view, the simple predicates are the ones which are projectible; and the problem with "grue" is that it isn't simple. But what is it for a predicate to be simple? One suggestionconsidered by Goodman-is that in the definition of simple predicates there is no reference to time. On this view, the problem with "grue" is that in its definition there is a reference to time.

However, Goodman notes that predicates like "green” could also be defined in a way that makes reference to time. To see this, he introduces the predicate "bleen" (p. 79) defined as follows:

An object is "bleen" if it is first examined before $t$ (some future time) and is blue; or is not first examined before $t$ and is green.

A projectible predicate like "green" can then be defined in a way that does refer to time:

An object is "green" if it is first examined before $t$ (some future time) and is grue; or is not first examined before $t$ and is bleen (p. 80).

Goodman concludes that the problem isn't that there is a reference to time in the predicate "grue".

\section{Goodman's Response}

How, then, does Goodman himself respond to the new riddle? 
Goodman considers actual projections that have been made in the past- these are the "raw material" of his discussion:

"The fact is that whenever we set about determining the validity of a given projection from a given base, we have and use a good deal of other relevant knowledge. I am not speaking of additional evidence statements, but rather of the record of past predictions actually made and their outcome. Whether these predictions - regardless of their success or failure-were valid or not remains in question; but that some were made and how they turned out is legitimately available information.” (p. 85)

Now, clearly "green" has figured many more times in our past projections than has "grue" (In fact, pre Goodman, "grue" had never appeared in our projections!). Goodman puts this point by saying that "green" is a more entrenched predicate than "grue" (p. 94).

Goodman claims that the hypothesis that all emeralds are green is regarded as projectible and the hypothesis that all emeralds are grue as unprojectible, because "green" is a much more entrenched predicate than "grue". His basic response to the new riddle is, then, effectively to say that valid inductive inferences are those that accord with those past regularities that we have picked out using our language; and that other inductive inferences are invalid.

But should we accept Goodman's response to the new riddle?

\section{A Problem with Goodman's Response}

What seems to be missing from his account is an explanation of why the projectible predicate "green" is entrenched, whereas the unprojectible predicate "grue” isn't. Indeed, Goodman does seem to regard this as something of a linguistic accident. He does not, for example, rule out the possibility of new predicates-like "grue"-becoming entrenched and therefore being projectible. His view seems, then, to be one according to which it just so happens that inductive inferences involving "green" are valid; whereas those involving "grue" are not.

I think Goodman's response needs to be supplemented. What we need and haven't yet got is an explanation of why "green" is entrenched and "grue" isn't. Goodman does seem to be aware of this problem: "Are we not trusting too blindly to a capricious Fate to see to it that just the right predicates get themselves comfortably entrenched? Must we not explain why, in cases of conflict like those illustrated, the really projectible predicate happens to have been the earlier and more often projected?” (p. 98) But no such explanation is offered.

\section{Why “Green” Is Entrenched, and “Grue” Isn't}

If we consider both projections actually made in the past and those that could have been made (but weren't), then "grue" and "green" are on a par. After all, every time in the past where "green” was projected, "grue” could also have been projected. Goodman's interest in distinguishing "grue" from "green" therefore naturally leads him to focus on projections that have actually been made in the past, rather than on those that could have been made (pp. 94-95). As he puts it: "The significant difference appears only if we consider just those occasions when each predicate was actually projected.” (p. 95).

But I think it is a mistake to completely disregard all projections that weren't, but could have been, made in the past. It seems to me that we do need to also consider projections that could have been made in the past but which would have been unsuccessful. These projections contain valuable information and so should also be part of the raw material of our discussion.

Past actual projections tell us which of the projections that could have been made in the past would have been unsuccessful. For example, consider a past successful projection actually made involving "green" at or before $\mathrm{t}^{*}\left(\mathrm{t}^{*}\right.$ is any fixed past time):

Premise: $\mathrm{N}$ emeralds are green.

Conclusion: The next emerald observed (after $t^{*}$ ) will be green.

Now consider the predicate "grue $\left(\mathrm{t}^{*}\right)$ " defined as follows:

An object is grue $\left(t^{*}\right)$ if it is first examined before $t^{*}$ and is green or is not first examined before $t^{*}$ and is blue.

Note that "grue $\left(\mathrm{t}^{*}\right)$ " is a function of the past time $\mathrm{t}^{*}$ (In a similar way, the original predicate "grue" could be thought of as a function of the future time $t$, and we could thus write "grue(t)" instead of "grue"). So, "grue( $\left(t^{*}\right)$ " is like grue, except that the time $\mathrm{t}^{*}$ is past. It is what we can call a "grue-like" predicate. In fact, what is being defined here is a range of grue-like predicates. If the past time $\left(\mathrm{t}^{*}\right)$ is given in calendar year, we are defining “grue(2011)”, "grue(2010)”, “grue (2009)” etc.

Although the past successful projection made at or before $t^{*}$ involved "green", the following projection could have been made at that time using "grue $\left(\mathrm{t}^{*}\right)$ ":

Premise: $\mathrm{N}$ emeralds are grue $\left(\mathrm{t}^{*}\right)$.

Conclusion: The next emerald observed (after $t^{*}$ ) will be grue $\left(\mathrm{t}^{*}\right)$.

Now, had this projection been made, it would have been unsuccessful. After all, after $t^{*}$ the next emerald will have been observed to be green, not blue; and so is not grue $\left(\mathrm{t}^{*}\right)$. (This is what the success of the past projection actually made involving "green” tells us).

The success of past actual projections involving "green" leads to the repeated use of "green" in our projections. In other words, it leads to its entrenchment. But these projections have taught us not to project using "grue(t*)", because for each occasion in the past when "green" was successfully projected, projections using "grue(t*)" would have been unsuccessful. This is valuable information that we should not (and do not) ignore. It clearly explains why "grue(t*)" isn't entrenched. Moreover, and importantly, it also explains why "grue” isn't entrenched. We don't seriously consider adopting "grue” in our projections because we realise that projections involving "grue$\left(t^{*}\right)$ " would not have worked in the past.

After all, imagine someone who recognises that past projecttions that could have been made using "grue $\left(t^{*}\right)$ " would all have been unsuccessful, but who nevertheless thinks that projections involving "grue" will be successful. For example, suppose that he recognises that "grue(2009)", "grue(2010)", "grue(2011)" etc are all unprojectible, but nevertheless thinks that "grue(2012)" will be projectible. We'd be inclined to think that he was crazy! He would need a good reason for thinking that the future will not be like the past-and what good reason does he have to think this?

\section{Conclusion}

We have, then, an explanation (missing in Goodman's ac- 


\section{LUBIN}

count) of why "green” is, and "grue” isn't, entrenched. Knowing that "grue-like" predicates would not have worked in the past, we don't adopt "grue” in our projections. But our not doing so is explicable. Indeed, it is rational. That "green" is entrenched and "grue" is not, is certainly no lucky linguistic accident.

\section{REFERENCES}

Carnap, R. (1947). On the application of inductive logic. Philosophy and Phenomenological Research, 8, 133-147. doi: $10.2307 / 2102920$

Goodman, N. (1983). Fact, fiction and forecast (4th ed.). Cambridge, MA: Harvard University Press. 